\title{
Optoelectronic properties of the Metal-dielectric complex thin films for applying high sensitivity IR image sensors
}

\author{
Yena Kim, Soon Woo Kwon, Seung Jun Park*, Woo Kyung Kim**, Han-Young Lee**, Dae Ho Yoon \\ and Woo Seok Yang**,t \\ School of Advanced Materials Science and Engineering, Sungkyunkwan University, Suwon 440-746, Korea \\ *Department of Materials Science and Engineering, Hanyang University, Seoul 133-791, Korea \\ **Korea Electronics Technology Institute, Bundang 463-816, Korea
}

(Received November 8, 2010)

(Revised November 24, 2010)

(Accepted December 24, 2010)

\begin{abstract}
High sensitivity IR image sensors require materials characteristics with temperature coefficient of resistance (TCR) and IR range absorption. In this study, the metal-dielectric thermo sensitive films (MDTF) based on $\left(\mathrm{SiO}_{2}\right)_{\mathrm{x}}-(\mathrm{Ti})_{\mathrm{y}}$ composition were deposited on substrates of germanium and glass by thermal evaporator. The $\mathrm{SiO}_{2}$ : $\mathrm{Ti}$ mixture was made from the ratio of $9: 1,8: 2,7: 3,6: 4$, respectively. $\left(\mathrm{SiO}_{2}\right)_{\mathrm{x}}-(\mathrm{Ti})_{\mathrm{y}}$ mixture powder was loaded on tungsten boat in evaporator and was $15.5 \mathrm{~cm}$ from the substrate. Resistance of $\left(\mathrm{SiO}_{2}\right)_{\mathrm{x}}-(\mathrm{Ti})_{\mathrm{y}}$ in the range of $273 \sim 333 \mathrm{~K}$ were measured as a function of temperature. Temperature coefficient of resistance (TCR) was calculated by the resistance variation. Under the various mixture ratios condition, it is possible to obtain $\mathrm{SiO}_{2}$-Ti layers with resistance from units kilo-ohm to hundreds kilo-ohm. Finally, our results showed that Temperature coefficient of resistance (TCR) of these films varies from -1.4 to $-2.6 \% \mathrm{~K}^{-1}$.
\end{abstract}

Key words $\left(\mathrm{SiO}_{2}\right)_{\mathrm{x}}-(\mathrm{Ti})_{\mathrm{y}}$ films, TCR, Resistivity, Thermal evaporator, IR image sensor

\section{고감도 적외선 이미지 센서 적용을 위한 금속-유전체 복합 박막의 광전자 특성}

김예나, 권순우, 박승준*, 김우경**, 이한영**, 윤대호, 양우석**,†

성균관대학교 신소재공학과, 수원, 440-746

*한양대학교 신소재공학과, 서울, 133-791

**전자부품연구원, 분당, 463-816

(2010년 11월 8일 접수)

(2010년 11월 24일 심사완료)

(2010년 12월 24일 게재확정)

요 약 고감도 적외선 이미지 센서에 적용이 가능한 우수한 TCR(temperature coefficient of resistance) 값을 갖고 적외선 파장영역에서 흡수 특성을 갖는 막 형성을 위해, 본 연구에서는 Silica와 Titanium 분말을 혼합비율을 달리하여 준비한 후 열 기상 증착기를 이용하여 상온에서 게르마늄과 유리 기판 위에 각각 $\left(\mathrm{SiO}_{2}\right)_{\mathrm{x}}-(\mathrm{Ti})_{\mathrm{y}}$ 막을 제작하였다. 챔버 내에 위치한 혼 합분말이 담겨진 텅스텐 보트와 기판 간의 거리는 $15.5 \mathrm{~cm}$ 이며, 사용된 $\mathrm{SiO}_{2}$ 와 $\mathrm{Ti}$ 분말의 혼합비율 $\mathrm{x}: \mathrm{y}$ 는 각각 $90: 10$, $80: 20,70: 30,60: 40$ 이다. $\left(\mathrm{SiO}_{2}\right)_{\mathrm{x}}-(\mathrm{Ti})_{\mathrm{y}}$ 막의 전기적 저항은 $273 \sim 333 \mathrm{~K}$ 영역에서 온도 변화에 따라 측정하였으며, $\mathrm{TCR}$ 값 은 측정된 막의 저항 값으로부터 계산되었다. 다양한 혼합비율 조건 하에서 형성된 $\left(\mathrm{SiO}_{2}\right)_{\mathrm{x}}-(\mathrm{Ti})_{\mathrm{y}}$ 막은 수 $\mathrm{k} \Omega$ 수백 $\mathrm{k} \Omega$ 의 저 항특성을 보였으며, 이러한 막의 $\mathrm{TCR}$ 은 $-1.4 \sim-2.6 \% \mathrm{~K}^{-1}$ 의 다양한 값을 나타내었다.

\section{1. 서 론}

비 냉각형 열 복사 감지기(uncooled thermal radiation detectors, TRDs)를 이용한 고감도 적외선 이미지 센서

\footnotetext{
Corresponding author

Tel: +82-31-789-7256

Fax: +82-31-789-7249

E-mail:wsyang@keti.re.kr
}

는 cryogenic 냉각이 필요 없어 센서 모듈의 무게 및 가 격을 낮출 수 있으며, 소형으로 제작이 가능해 자동차 안전 시스템, 보안 및 군수용 나이트 비전 등으로의 적 용을 위해 많은 연구 및 개발이 진행되고 있다[1-3]. 이러 한 비 냉각형 열 복사 감지기는 thermocouple, bolometer, acousto-optic, pyro-electric 등을 이용한 방식이 있으며, 이 중 Bolometer 방식의 경우 기존의 MEMS(Micro Electrical Mechanical System)기술을 이용하여 비교적 
쉽게 제작이 가능하며, 또한 초소형으로의 소자구현이 용이해 가장 연구가 활발한 분야이다[4-6].

일반적으로 마이크로 볼로메터 방식에서 구성되는 감 지요소는 높은 저항의 온도계수(Temperature Coefficient of Resistance, TCR) 값을 갖는 온도 감응층과 흡수층으 로 구성되어 있다. 온도 감응층의 경우 $\mathrm{VO}_{2}$ 와 같은 바 나듐 산화물 박막 또는 a-Si와 같은 비정질 반도체 박막 이 주로 사용되고 있으며, 흡수층의 경우 금속 박막의 단일층 또는 복층 구조로 구성하여 적외선 대역에서의 흡수율을 $50 \sim 90 \%$ 정도로 도달하는 것이 가능하다[710]. 그러나, 이러한 이종 물질로 이루어진 복층 박막을 이용할 경우 마이크로 볼로메터의 열 용량을 계속적으로 증가시켜 센서의 구동 성능을 저해할 수 있으며, 또한 제작 공정 중 형성된 이종물질 간 상호 확산 등의 반응 및 상이한 식각 메커니즘에 의해 소자의 수율 및 특성 저해를 유발시킬 수 있다. 따라서, 기존의 감응층과 흡수 층으로 이루어진 복층 구조를 두 가지 특성을 모두 갖는 소재를 이용한 단일 구조 박막으로 대체하고, 이을 통해 제조공정의 단순화 및 이종물질 다층 박막으로 인해 일 어날 수 있는 소자 성능이 저해되는 문제점 등을 해결하 고자 하는 것은 초소형 고감도 적외선 이미지 센서 적용 을 위한 마이크로 볼로메터 구현에 있어 매우 중요하다. 이러한 관점에서 높은 $\mathrm{TCR}$ 값을 갖고 적외선 영역에서 흡수를 갖는 소재의 막 형성 및 광학적, 전기적 특성 등 에 관련한 연구는 매우 필요하다[11].

따라서, 본 연구에서는 Silica와 Titanium 분말을 이용 하여 혼합비율에 따른 $\left(\mathrm{SiO}_{2}\right)_{\mathrm{x}}-(\mathrm{Ti})_{\mathrm{y}}$ 막을 제조하였으며, 다양한 조건 하에서 형성된 막의 광학 및 전기적 특성을 분석하여 고감도 적외선 이미지 센서로의 적용가능성을 검토하였다.

\section{2. 실험방법}

열 기상 증착기를 이용하여 $\left(\mathrm{SiO}_{2}\right)_{\mathrm{x}}-(\mathrm{Ti})_{\mathrm{y}}$ 막을 약 $0.83 \mu \mathrm{m}$ 의 두께로 상온에서 증착하였다. 이때 증착 조건은 초기 진공도 $2 \times 10^{-5}$ torr이며, 기판과 증발 원 사이의 간격은 약 $15.5 \mathrm{~cm}$ 이다. 막 증착을 위해 사용된 원료는 순도 $99.99 \%$ 와 $99.95 \%$ 의 $\mathrm{SiO}_{2}$ 와 $\mathrm{Ti}$ 파우더를 혼합 분쇄하 여 이용하였으며, 혼합된 원료의 무게 비 $\mathrm{x}: \mathrm{y}$ 는 각각 $90: 10,80: 20,70: 30,60: 40$ 이다. 준비된 시료는 약 $0.15 \sim 0.3 \mathrm{~mm}$ 두께를 갖는 molybdenum 튜브에 혼합비 율에 따라 장입 후 막 형성을 수행하였다. 또한 초기 $\mathrm{SiO}_{2}$ 와 $\mathrm{Ti}$ 의 입자 크기는 약 $100 \mathrm{mesh}$ 이다. 막 형성을 위해 이용된 기판은 두 가지 종류이며, 적외선 영역에서 막의 투과율 측정을 위해서는 7 15 $\mu \mathrm{m}$ 적외선 영역에 서 흡수가 없는 anti-refraction 층이 코팅된 게르마늄 기
판, $\mathrm{TCR}$ 과 면 저항 $(\mathrm{Rs})$ 측정을 위해서는 Glass 기판을 이용하였다. 기판은 $\mathrm{NH}_{4} \mathrm{OH}(25 \%), \mathrm{H}_{2} \mathrm{O}_{2}(30 \%), \mathrm{H}_{2} \mathrm{O}$ (distillated)으로 구성된 수소 암모늄 혼합물 내에 위치시 킨 후 약 $60^{\circ} \mathrm{C}$ 의 온도에서 1 시간 동안 초음파로 세척 후 증착을 수행하였다. 적외선 투과특성은 $7 \sim 15 \mu \mathrm{m}$ 파 장 영역에서 Thermo Electron사의 FT-IT(Fourier Transform Infrared Spectroscopy, NICOLET 2700)을 이용하여 게 르마늄 기판 위에 형성된 $\left(\mathrm{SiO}_{2}\right)_{\mathrm{x}}-(\mathrm{Ti})_{\mathrm{y}}$ 막을 측정하였다. 저항과 TCR(temperature coefficient of resistance) 등의 $\left(\mathrm{SiO}_{2}\right)_{\mathrm{x}}-(\mathrm{Ti})_{\mathrm{y}}$ 막의 열 감지 특성은 glass 기판 위에 형성 된 막을 이용하였다. 막 위에 금 막을 약 $100 \mathrm{~nm}$ 의 두 께로 증착 후 $5 \mathrm{~mm}^{2}$ 면적을 갖는 $2 \mathrm{D}$ 형태의 monopixels을 photo-lithography 및 식각 공정을 통하여 제작 한 후 probe station과 SCS- 4200 를 이용하여 273부터 $333 \mathrm{~K}$ 까지 $5^{\circ} \mathrm{C}$ 간격으로 온도를 변화시키면서 각각의 온도구간에서의 I-V curve를 측정하고 특정한 bias에서 의 저항 값을 추출한 결과로부터 TCR 값을 도출하였다. 면 저항 $(\mathrm{Rs})$ 의 경우는 4 point probe를 이용하여 측정하 였다. 또한 $\left(\mathrm{SiO}_{2}\right)_{\mathrm{x}}-(\mathrm{Ti})_{\mathrm{y}}$ 막의 $\mathrm{x}$ 와 $\mathrm{y}$ 의 혼합무게 비에 따른 막의 표면형상 변화를 SEM(Scanning Electron Microscopy)를 이용하여 관찰하였다.

\section{3. 결과 및 고찰}

Fig. 1 에 $\mathrm{SiO}_{2}$ 와 $\mathrm{Ti}$ 의 혼합비율에 따라 상온에서 실리 콘 기판 위에 열 기상 증착기를 이용하여 형성된 막의 전자현미경 사진을 나타내었다. $\left(\mathrm{SiO}_{2}\right)_{\mathrm{x}}-(\mathrm{Ti})_{\mathrm{y}}$ 막의 표면 은 cluster 형태를 갖추고 있었으며, 이는 Ti의 혼합비율 이 증가할수록 그 크기가 감소하는 경향을 관찰할 수 있 었다.

열 기상 증착법 등과 같은 물리적 기상 증착기를 통해 박막을 증착할 경우 증착층의 조직은 기판의 온도 함수 로 작용하는 원자의 유동 조건 및 기판과 증발물의 온도 에 의해 결정된다고 알려져 있다. $\left(\mathrm{SiO}_{2}\right)_{\mathrm{x}}-(\mathrm{Ti})_{\mathrm{y}}$ 막의 경 우 상온에서 증착을 진행함으로 인해 형성되는 막의 단 위면적당 표면에너지가 기지기판( $\mathrm{Si}$, Glass wafer) 보다 높으며, 기판과의 격자불일치가 크기 때문에 cluster가 형성되어 성장한 것으로 보인다.

Fig. 2에 anti-refraction 층이 코팅된 게르마늄 기판 위 에 형성된 $\mathrm{SiO}_{2}-\mathrm{Ti}$ 막의 적외선 영역에서의 투과 특성을 나타내었다. 측정된 막의 두께는 $0.83 \mu \mathrm{m}$ 이며, $\mathrm{SiO}_{2}$ 와 $\mathrm{Ti}$ 의 혼합무게 비는 $80: 20$ 이다. $\left(\mathrm{SiO}_{2}\right)_{80}-(\mathrm{Ti})_{20}$ 막은 약 $8 \sim 12 \mu \mathrm{m}$ 의 적외선 영역에서 걸쳐 폭이 넓은 흡수밴드 특성을 보이고 있으며, 이러한 밴드 특성은 $\mathrm{SiO}-\mathrm{O}$ 본드 의 진동모드에 부합한다[12].

기존의 마이크로 볼로메터에 적용하고 있는 감응층과 


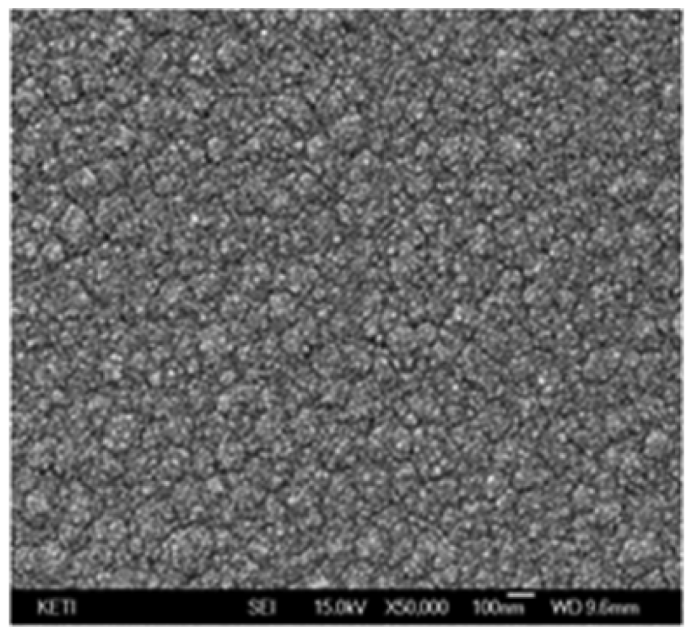

(a)

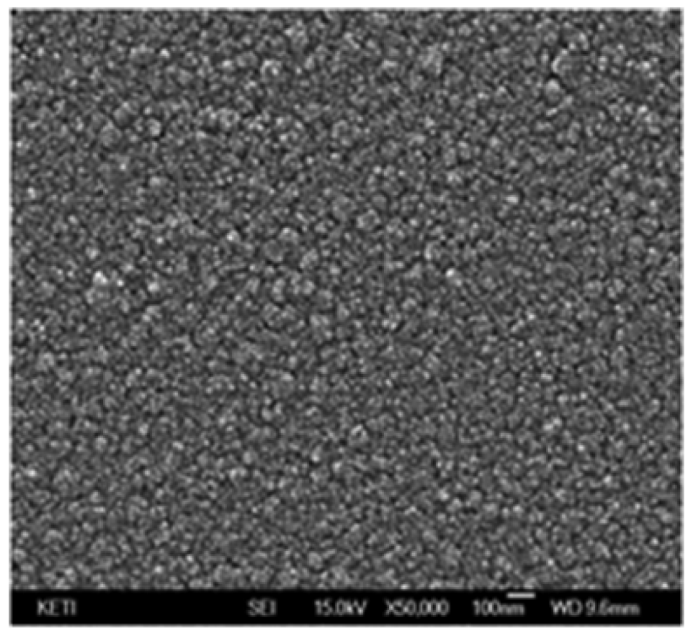

(c)

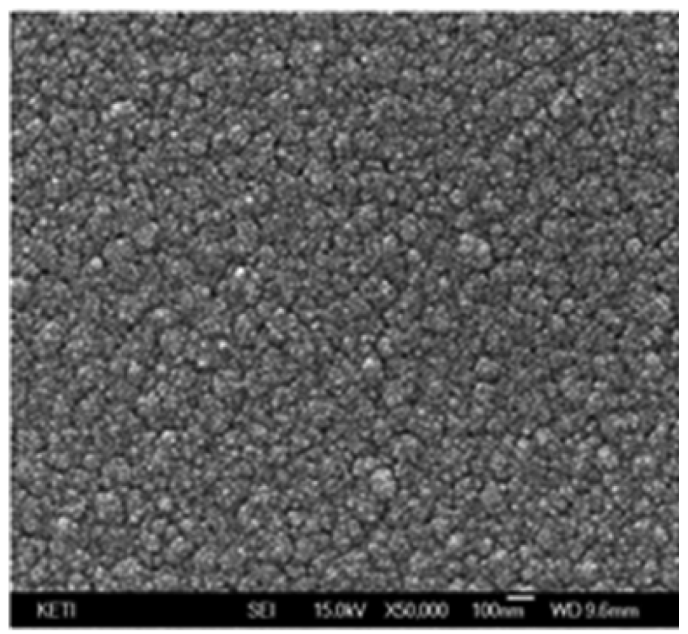

(b)

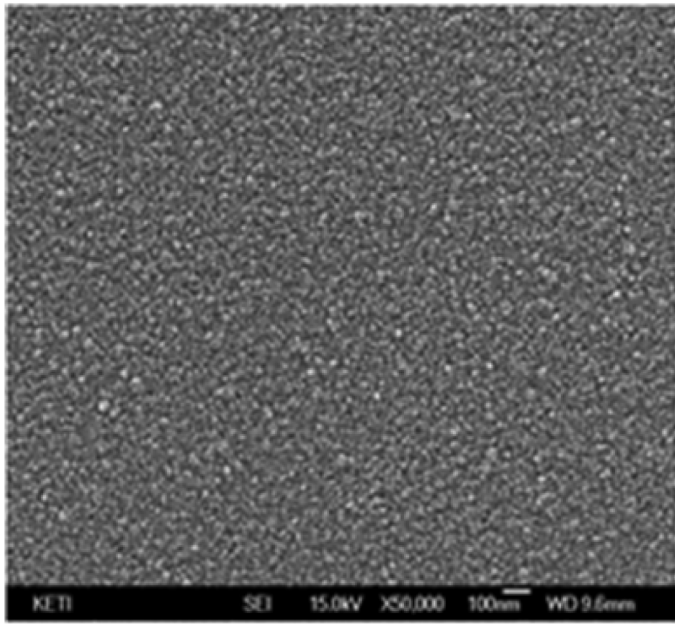

(d)

Fig. 1. Surface images of $\left(\mathrm{SiO}_{2}\right)_{\mathrm{x}}-(\mathrm{Ti})_{\mathrm{y}}$ films; (a) $\left(\mathrm{SiO}_{2}\right)_{90}-(\mathrm{Ti})_{10}$, (b) $\left(\mathrm{SiO}_{2}\right)_{80}-(\mathrm{Ti})_{20}$, (c) $\left(\mathrm{SiO}_{2}\right)_{70}-(\mathrm{Ti})_{30},(\mathrm{~d})\left(\mathrm{SiO}_{2}\right)_{60}-(\mathrm{Ti})_{40}$.

흡수층으로 이루어진 복층 구조의 센서물질을 두 가지 특 성을 모두 가지고 있는 단일 구조 박막으로의 구현을 위 해 $8 \sim 12 \mu \mathrm{m}$ 영역에서 적외선 흡수 특성을 가지고 있는 $\left(\mathrm{SiO}_{2}\right)_{\mathrm{x}}-(\mathrm{Ti})_{\mathrm{y}}$ 막의 TCR 특성에 관한 연구를 수행하였다.

일반적으로 적외선 이미지 센서에 적용을 위한 마이크 로 볼로메터의 동작은 응답과 노이즈에 의해 결정된다. 응답은 입력되는 IR 파워에 비례하여 출력되는 전압신 호로 정의되며, 아래의 식으로 표현된다[13].

$$
\mathrm{R}_{\mathrm{V}} \propto \propto \eta \mathrm{V} / \mathrm{G} \text {, }
$$

$\mathrm{R}_{\mathrm{V}}$ 는 전압응답, $\alpha$ 는 $\mathrm{TCR}$ (temperature coefficient of resistance), $\eta$ 는 볼로메터의 방사율, $\mathrm{V}$ 는 bias 전압, $\mathrm{G}$ 는 열전도율을 나타낸다. 상온에서의 TCR은 아래의 식 으로 계산된다.

$$
\begin{aligned}
& \alpha=1 / \mathrm{R}_{0} \cdot \mathrm{dR} / \mathrm{dT}=-\mathrm{Ea} / \mathrm{kT}^{2}, \\
& \mathrm{R}_{0} \text { 는 상온에서의 저항, } \mathrm{k} \text { 는 볼츠만 상수, } \mathrm{Ea} \text { 는 활성화 }
\end{aligned}
$$

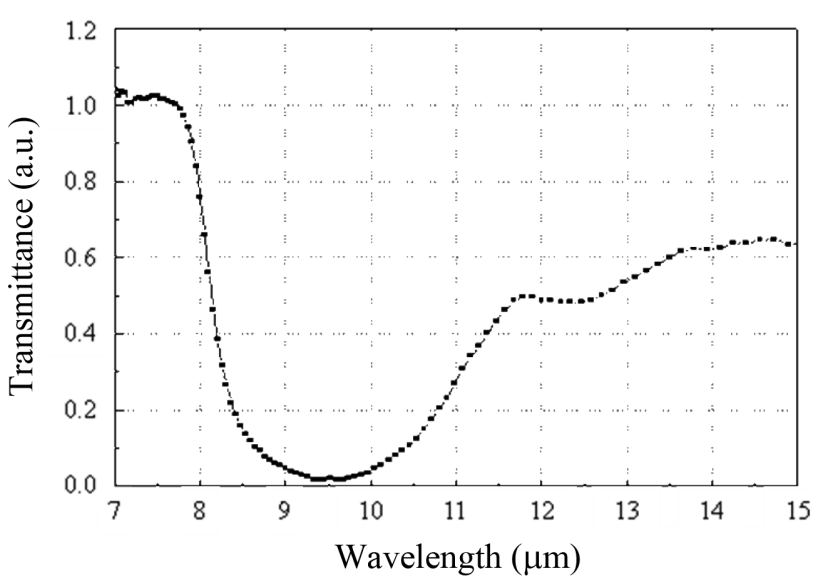

Fig. 2. Transmittance of $\left(\mathrm{SiO}_{2}\right)_{80}-(\mathrm{Ti})_{20}$ film (thickness of the film is $0.83 \mu \mathrm{m})$.

에너지를 나타낸다.

열전도는 볼로메터의 열 차단구조에 의존적이며, 이러 


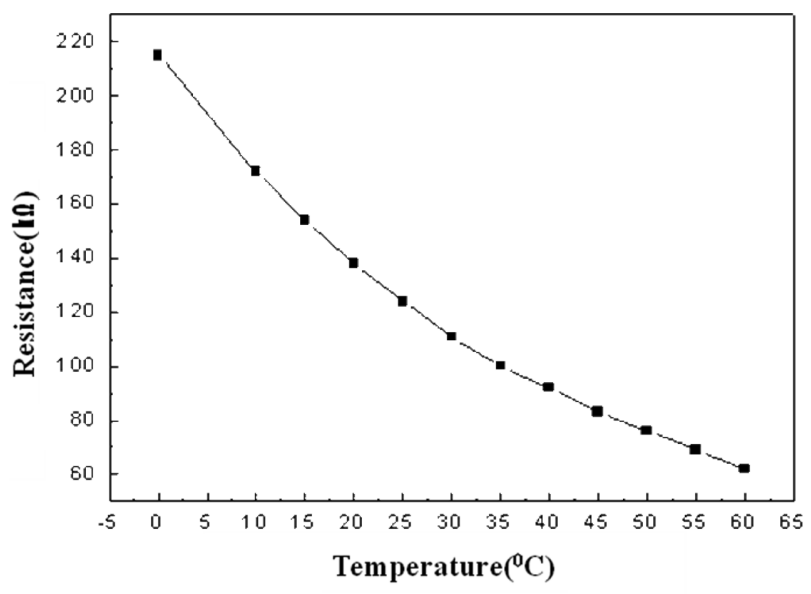

(a)

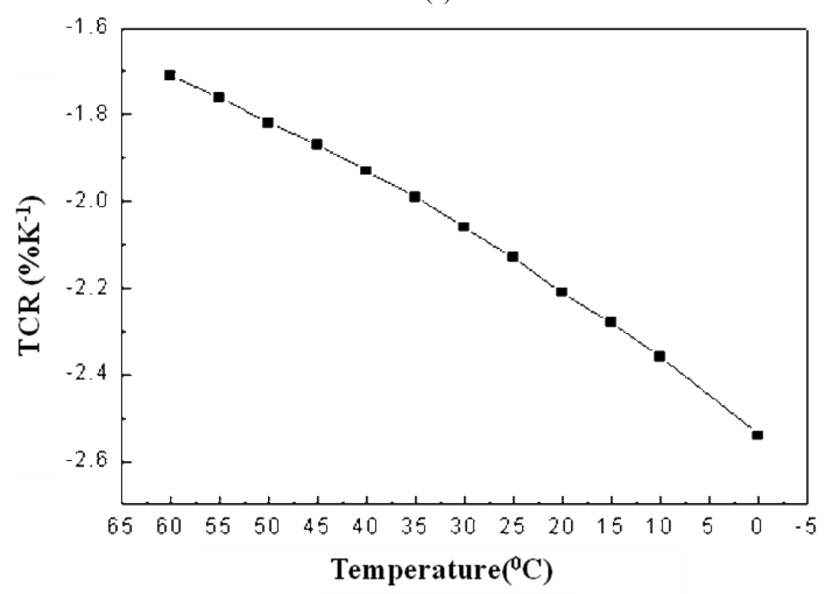

(b)

Fig. 3. Resistance $(\mathrm{R})$ of $\left(\mathrm{SiO}_{2}\right)_{80}-(\mathrm{Ti})_{20}$ film and temperature dependence of TCR.

한 열 차단구조의 최적화를 통해 증가시킬 수 있으며, 적외선 흡수 경우는 $\lambda / 4$ cavity 구조의 설계 및 제작을 통해 증가시킬 수 있다. 그러나, TCR의 경우는 재료의 기본 물리적 특성이며, 그것은 단지 재료의 물성에 의존 한다.

Fig. 3과 4에 온도 변화에 따른 $\left(\mathrm{SiO}_{2}\right)_{\mathrm{x}}-(\mathrm{Ti})_{\mathrm{y}}$ 막의 저 항특성 및 TCR 특성을 나타내었다. $\left(\mathrm{SiO}_{2}\right)_{\mathrm{x}}-(\mathrm{Ti})_{\mathrm{y}}$ 함유량 에 따라 $\left(\mathrm{SiO}_{2}\right)_{90}-(\mathrm{Ti})_{10}$ 막은 $\mathrm{Ti}$ 의 비율이 낮아 부도체의 특성을 보이고 $\left(\mathrm{SiO}_{2}\right)_{60}-(\mathrm{Ti})_{40}$ 막은 $\mathrm{Ti}$ 의 비율이 높아짐에 따라 도체의 성질을 나타내었다. $\left(\mathrm{SiO}_{2}\right)_{90}-(\mathrm{Ti})_{10}$ 막은 저항 이 측정되지 않았고 $\left(\mathrm{SiO}_{2}\right)_{60}-(\mathrm{Ti})_{40}$ 막은 $\mathrm{TCR}$ 특성이 나 타나지 않았다. 따라서 측정을 위해 이용된 막의 $\mathrm{SiO}_{2}$ 와 $\mathrm{Ti}$ 의 무게 비는 $80: 20$ 과 $70: 30$ 이며, 형성된 막의 두께 는 모두 $0.86 \mu \mathrm{m}$ 이다.

$\left(\mathrm{SiO}_{2}\right)_{80}-(\mathrm{Ti})_{20}$ 막의 경우(Fig. 3) 온도의 증가에 따른 저항의 변화는 지수함수적으로 감소하는 경향을 나타내 었다. 이러한 값을 통해 계산된 $\mathrm{TCR}$ 은 음의 값을 나타 내었으며, 그 값은 상온에서 약 $-2.21 \% \mathrm{~K}^{-1}$ 이었다. 음의 $\mathrm{TCR}$ 값과 저항의 지수함수적 감소는 $\mathrm{SiO}_{2}-\mathrm{Ti}$ 막 내에서

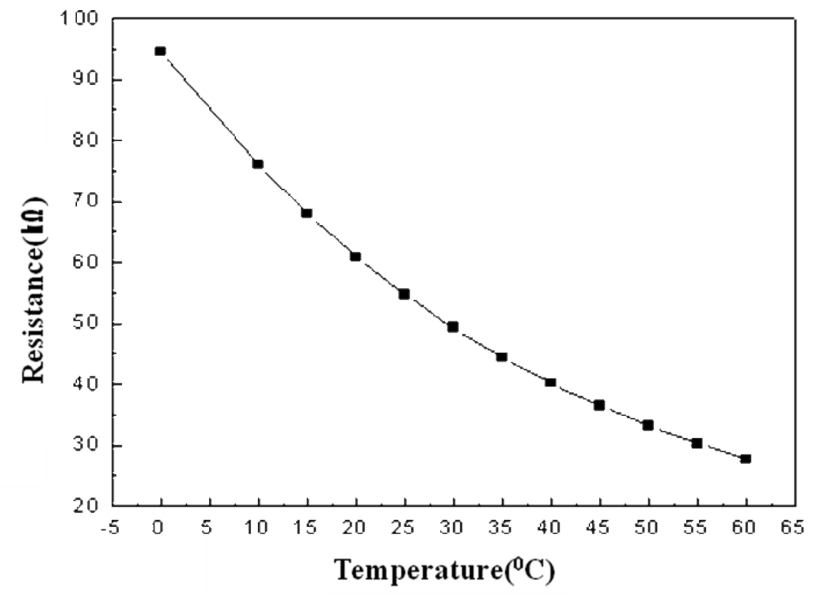

(a)

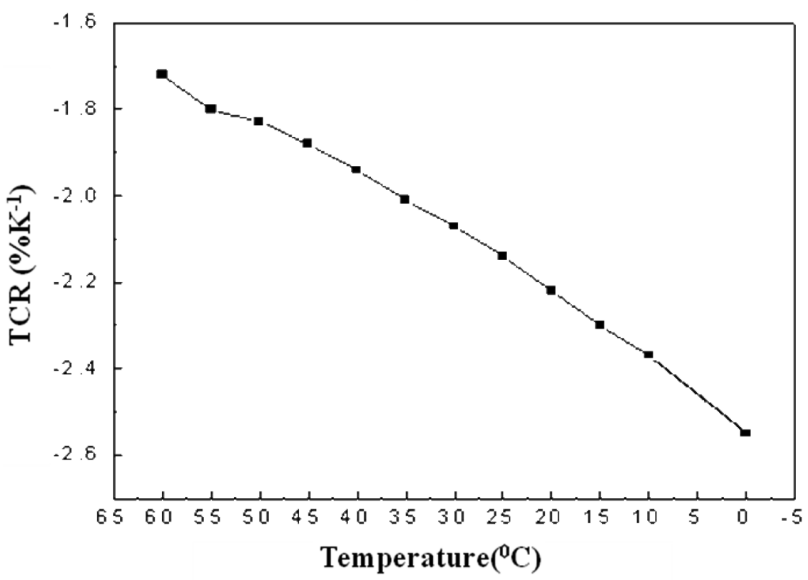

(b)

Fig. 4. Resistance $(\mathrm{R})$ of $\left(\mathrm{SiO}_{2}\right)_{70}-(\mathrm{Ti})_{30}$ film and temperature dependence of TCR.

퍼콜레이션 채널들과 같은 것을 통한 터널 전도와 흡사 한 전도 메커니즘과 관계가 있은 것으로 보이며, 이는 비슷한 조성의 $\mathrm{Au}-\mathrm{SiO}$ 도성합금 박막들 내에서 보이는 전도 메커니즘과 유사할 것으로 생각된다[14]. 다른 혼 합비로 형성된 $\left(\mathrm{SiO}_{2}\right)_{70}-(\mathrm{Ti})_{30}$ 막의 경우(Fig. 4) 온도에 따른 저항의 변화를 측정한 결과 같은 두께의 $\left(\mathrm{SiO}_{2}\right)_{80^{-}}$ $(\mathrm{Ti})_{20}$ 막과 비교하여 온도에 따른 저항 값이 약 두 배정 도 감소되는 것을 확인 할 수 있었으며, TCR 값은 상온 에서 약 $-2.22 \% \mathrm{~K}^{-1}$ 이었다.

\section{4. 결 론}

마이크로 볼로메터 적용이 가능한 적외선 영역에서의 흡수 및 온도변화에 따른 높은 저항변화 특성을 모두 갖 는 단일층 형성을 위해 열 기상 증착법을 이용하여 다양 한 혼합비율을 갖는 $\left(\mathrm{SiO}_{2}\right)_{\mathrm{x}}-(\mathrm{Ti})_{\mathrm{y}}$ 막을 형성하였다. 형성 된 막의 표면 특성 및 온도변화에 따른 저항변화를 측정 하였으며, 이 저항 값을 이용하여 상온에서의 TCR값을 
계산하였다. 결과적으로 형성된 $\left(\mathrm{SiO}_{2}\right)_{\mathrm{x}}-(\mathrm{Ti})_{\mathrm{y}}$ 막은 8 $12 \mu \mathrm{m}$ 의 적외선 영역에서 넓은 흡수 특성을 가졌으며, 수 $\mathrm{k} \Omega$ 수백 $\mathrm{k} \Omega$ 의 저항특성을 보였다. 또한 막의 $\mathrm{TCR}$ 은 증착 조건에 따라 $-1.4 \sim-2.6 \% \mathrm{~K}^{-1}$ 의 다양한 값을 얻 을 수 있었다.

\section{참 고 문 헌}

[ 1 ] J.M. Lloyd, "Themal Imaging Systems", Plenum Press, New York (1975).

[2 ] J.L. Miller, "Principles of Infrared Technology", Van Nostrum Reinhold, New York (1994).

[3 ] R.S. Balcerak, "Uncooled IR imaging: technology for the next generation", Infrared Technol. Appl. XXV, SPIE 3698 (1999) 110.

[ 4 ] P.G. Datskos, N.V. Lavrik and S. Rajic, "Performance of uncooled microcantilever thermal detectors", Rev. Sci. Instrum 75 (2004) 1134

[ 5 ] S.R. Hunter, G. Maurer, L. Jiang and G. Simelgor, "Highsensitivity uncooled microcantilever infrared imaging arrays", Proc. SPIE, 6206 (2006) 620 61J-1-620 61J-11.

[6] D. Grbovic et al., "Uncooled infrared imaging using bimaterial microcantilever arrays", Appl Phys. Lett. 89
(2006) 073118.

[7] V. Yu. Zerov et al., "Features of the operation of a bolometer based on a vanadium dioxide film in a temperature interval that includes a phase transition", J. Opt. Technol. 66 (1999) 387.

[ 8 ] C. Chen, X. Yi, J. Zhang and X. Zhao, "Linear uncooled microbolometer array based on $\mathrm{VO}_{\mathrm{x}}$ thin films", Infrared Phys. Technol. 42 (2001) 87.

[9] K.C. Liddiard, "Thin-film resistance bolometer IR detectors - II", Infrared Physics 26 (1986) 43.

[10] K.C. Liddiard, M.H. Unewisse and O. Reinhold, "Design and fabrication of thin film monolithic uncooled infrared detector arrays", SPIE, 2225 (1994) 62.

[11] E.V. Michailovskaya, I.Z. Indutnyy and P.E. Shepeliavyi, "Inhomogeneous $\mathrm{SiOx}<\mathrm{Fe}>$ metal-dielectric films as a material for infrared thermal radiation detectors", Technical Physics 48(2) (2003) 261.

[12] K. Haga and H. Watanabe, "A structural interpretation of Si---O---Si vibrational absorption of high-photoconductive amorphous $\mathrm{a}_{-\mathrm{SiO}_{x}}: \mathrm{H}$ films", 195(1-2) (1996) 72.

[13] J.D. Vinent, "Fundamentals of infrared detector operation and testing", Wiley (1990).

[14] J.E. Morris, "Structure and electrical properties of AuSiO thin film cermets", Thin Solid Films 11 (1972) 299. 